\title{
EL ROL DE LAS DEFENSORÍAS DEL PUEBLO EN LA NUEVA AGENDA DE DERE- CHOS HUMANOS Y SUS DESAFÍOS REGIONALES EN EL SIGLO XXI. HOMENAJE A HÉCTOR GROS ESPIELL*
}

\author{
THE ROLE OF OMBUDSMAN'S OFFICES IN THE NEW HUMAN RIGHTS ANGEN- \\ DA AND REGIONAL CHALLENGES IN THE 21 st CENTURY. \\ A TRIBUTE TO HÉCTOR GROS ESPIELL
}

\section{O ROL DAS DEFENSORIAS DO POVO NA NOVA AGENDA DOS DIREITOS HU- MANOS E OS DESAFIOS REGIONAIS NO SÉCULO XXI. HOMENAGEM AO Dr. HÉCTOR GROS ESPIELL}

Carlos Contenla**

I

Entre los días 2 y 4 de junio de 1983, en ocasión de conmemorarse el bicentenario del nacimiento del libertador Simón Bolívar, se realizó el primer coloquio hispanoamericano sobre la figura del Ombudsman. Se lo tituló El Ombudsman para América Latina. Fueron jornadas de intenso trabajo que tras varias disertaciones y posteriores debates concluyeron con la creación del Instituto Latinoamericano del Ombudsman - Defensor del Pueblo, hoy Instituto Latinoamericano del Ombudsman - Defensorías del Pueblo (ILO).

*Conferencia Magistral dictada en el marco del Seminario Regional sobre el "Rol de las Defensorías del Pueblo en la nueva agenda de los Derechos Humanos y sus desafíos regionales en el siglo XXI", llevado a cabo en la Facultad de Derecho UDELAR el 6 de diciembre 2019 en el marco del X homenaje a su fallecimiento. El Seminario fue organizado por ILO y contó con el apoyo de la INDDHH y el auspicio de la Defensoría de las Vecinas y Vecinos de MVD; la Facultad de Derecho de la UDELAR. En el marco de dicho Seminario fue instalado el CAPÍTULO URUGUAYO del Instituto Latinoamericano del ILO, en Asamblea realizada en el Palacio Legislativo el mismo día 6 de diciembre de 2020.

\footnotetext{
*Conferencia Magistral dictada en el marco del Seminario Regional sobre el "Rol de las Defensorías del Pueblo en la nueva agenda de los Derechos Humanos y sus desafíos regionales en el siglo XXI", llevado a cabo en la Facultad de Derecho UDELAR el 6 de diciembre 2019 en el marco del X homenaje a su fallecimiento. El Seminario fue organizado por ILO y contó con el apoyo de la INDDHH y el auspicio de la Defensoría de las Vecinas y Vecinos de MVD; la Facultad de Derecho de la UDELAR. En el marco de dicho Seminario fue instalado el CAPÍTULO URUGUAYO del Instituto Latinoamericano del ILO, en Asamblea realizada en el Palacio Legislativo el mismo día 6 de diciembre de 2020.

**Presidente Emérito del Instituto Latinoamericano del Ombudsman. Defensor del Pueblo de Vicente Provincia de Buenos Aires 1999-2009. Ex profesor de la Universidad de Buenos Aires. Profesor invitado de la materia Defensorías del Pueblo en la Universidad Nacional de Córdoba. Correo electrónico: crconstenla@gmail.com
} 
**Presidente Emérito del Instituto Latinoamericano del Ombudsman. Defensor del Pueblo de Vicente Provincia de Buenos Aires 1999-2009. Ex profesor de la Universidad de Buenos Aires. Profesor invitado de la materia Defensorías del Pueblo en la Universidad Nacional de Córdoba. Correo electrónico: crconstenla@gmail.com

Quienes habían programado y organizado aquél ya lejano encuentro, resolvieron que la conferencia referencial, introductoria al tema del Ombudsman, estuviera a cargo del Dr. Héctor Gros Espiell. Años más tarde el mismo Gros Espiell, que había sido el primer conferenciante de ILO, llegaría a ser su presidente.

Puede decirse de este modo, que la palabra de Gros Espiell fue institucionalmente la primera que planteó las razones, el sentido y la oportunidad para que hubiese un Ombudsman en Latinoamérica.

Es así entonces que el ILO, se honra estando presente hoy en Montevideo, para rendir homenaje, a diez años de su fallecimiento, a uno de sus fundadores, a uno de sus presidentes y a uno de los que primero laboró desde la tribuna de su saber, la construcción de las defensorías del pueblo de nuestra América.

No vengo a hacer la semblanza de Gros Espiell. Otros -quienes lo conocieron más- lo podrán hacer con mayor autoridad. Sólo estuve con él una mañana en su casa de Pocitos cuando, acompañado por mis apreciados amigos Álvaro Garcé, entonces Comisionado Parlamentario para el Sistema Penitenciario y Fernando Rodríguez, Defensor de los Vecinos de Montevideo, fui a ofrecerle en nombre de la Directiva de ILO, integrar su Consejo Honorario.

Tengo en mi poder, por la diligencia archivística de quien fue nuestro Secretario General por décadas, el ingeniero Isaac Hochman, el texto de la presentación de Gros Espiell y en torno a sus ideas y valoraciones sobre esta institución, desarrollaré mi exposición, porque creo que a diez años de su fallecimiento, es una demanda ética y de toda justicia trasmitir con la mayor fidelidad, qué pensaba el gran jurista uruguayo de esta institución cuando era aún nonata.

Los conceptos que escucharán son las palabras iniciales de una institución que después se desarrollaría en todo el continente. Por momentos tienen la certeza que alimenta el saber y en otros las vacilaciones que anima la duda, tan científico uno como la otra. Pero siempre señalando un hilo conductor que atado en los cimientos de la República, conducen al derecho y la libertad empleando dos conceptos que eran para él primordiales para la convivencia en sociedad.

A treinta y seis años de distancia puede resultar fácil señalar discrepancias crecidas al calor de la historia misma de la institución como de otras miradas sobre su naturaleza jurídica y la visión sociológica que atempera el rigor del derecho. Pero no hallé en el texto un solo anacronismo, ni una verdad a medias, ni una opinión que nos obligue a mirar hacia otro lado. Tómense entonces mis palabras como un sentido de homenaje, de valoración 
jurídica y de reconocimiento hacia quien hizo ciencia con el derecho y, en su caso particular, una forma de vida.

II

Se pregunta Gros de forma liminar si es posible, útil y necesario pensar en la adopción de un Ombudsman, "en esta América difícil y conflictiva, desgarrada por hondos y seculares problemas políticos, económicos y sociales, con graves crisis institucionales, agónica en una palabra, en la acepción de agonía como concepto de lucha vital y de búsqueda angustiosa, que Unamuno rescató para nuestro idioma común”.

Advierte que este instituto se ha difundido y adoptado en "países de muy diversos grados de cultura, tradición jurídica y ubicación geográfica”, dejando entrever la duda que plantea su recepción en nuestro continente. Se debe tener presente que a ese momento, no existía ningún ombudsman en América Latina. Pero hace aquí su primera acogida al afirmar que "Cada día se comprende mejor que su establecimiento responde excepcionalmente bien a muchas de las circunstancias que caracterizan hoy las consecuencias del creciente desbordamiento de la actividad administrativa, de las crisis de los sistemas tradicionales de control jurisdiccional y de la necesidad de una mejor, más simple, menos formal, más rápida y más eficaz defensa de los derechos de los individuos frente al poder público". Hoy podríamos discutir algunos aspectos de esta definición, pero en el tiempo en el que es dicha es impecable. Más aún, diríamos hoy que le faltan cosas, pero que no le sobra nada.

Gros Espiell se da tempranamente cuenta que la misión del ombudsman supera a una época, a un sistema o a un modelo, de alguna manera escapa a la versión dogmática del ombudsman clásico, al emparentarlo con otras épocas, con otros sistemas o con otros modelos. Así alude a la Prokuratura rusa, establecida por el zar Pedro el Grande, eliminada por la Revolución de 1917 y luego restablecida por Lenin. La comparación se la echarán en cara algunos ponentes posteriores con argumentos políticos, pero sin poder rebatirlo con razones jurídicas.

Otra contribución importante para dar a luz al Ombudsman en América Latina fue señalar que sus raíces eran ajenas a la tradición jurídica de los sistemas presidencialistas, pero que esto a la postre no sería un impedimento definitivo. La situación económica y social había cambiado porque se había llegado a la convicción de "que el verdadero desarrollo sólo es posible si se realiza aceptando los contralores jurídicos y si se armoniza con la protección y garantía de los derechos humanos”. Es aquí donde Gros Espiell emparienta al Ombudsman con los derechos humanos con una mirada claramente transgresora al modelo tradicional del Ombudsman europeo. Rápidamente vuelve sin embargo a la idea clásica: “A mi juicio, todo análisis de la institución del Ombudsman debe comenzar por situarla dentro del conjunto de regímenes; sistemas o procedimientos destinados a asegurar el control jurídico del Poder Público en general y de la Administración en particular. Estos sistemas 
o procedimientos, por diferentes vías o mediante distintas fórmulas tienen como objetivo esencial el de hacer realidad la existencia de un Estado de Derecho en el que la seguridad jurídica sirva de fundamento a la libertad en un orden integral de justicia". El Ombudsman, sería entonces el "control de la Administración y la protección de individuo".

La condición no jurisdiccional de esta institución no significa para Gros la eliminación de los recursos tradicionales. "No se trata de plantear una opción, sino de resolver un problema de armonización y coordinación en función del objetivo esencial: fortalecer y hacer más eficaz el sistema institucional para que el Estado de Derecho sea una realidad veraz y viva". "La verdad es que la institución se ha desarrollado con gran empuje en los últimos tiempos como consecuencia de la ineficiencia del sistema tradicional de garantías jurisdiccionales, frente a la acción progresivamente creciente en intensidad y en amplitud de la Administración".

No escapó a su observación la crisis del sistema político representativo, en este caso relacionada a las responsabilidades de control que incumben a los cuerpos legislativos. Aquí avanza con otra caracterización de esta figura: "el Ombudsman es un órgano vinculado al Poder Legislativo, sin atribuciones estrictas de control político, garante del correcto uso del Poder Administrativo, que asegura el buen proceder de la Administración y la defensa de los derechos lesionados por la actividad administrativa. El Ombudsman no integra el Parlamento, no está sometido a las instrucciones de éste, es apolítico, imparcial y objetivo, tanto por el régimen de su designación, que en general obliga a un acuerdo interpartidario, como por lo relativo a la duración de su mandato y a la independencia de sus funciones. Por lo demás, su autonomía de acción está en general reforzada por la discrecionalidad de que goza en la organización de su despacho, en la elección de sus colaboradores y en la dirección y desempeño de sus actividades. Sus poderes no son de revisión ni de anulación. Han sido calificados como el poder de persuasión y de la influencia respecto de la autoridad administrativa, el poder de adoptar iniciativas para plantear la corrección de actos irregulares o lesivos de estas autoridades y el poder de dar a conocer sus críticas y sugerencias".

Gros Espiell se adelantó a un debate que iba a concluir recién en los primeros años del siglo XXI. Sostenía que el Ombudsman no sólo debía de preocuparse para proteger los derechos civiles y políticos de las personas sino también de sus derechos económicos, sociales y culturales porque entendía que sólo así se podría pasar de una democracia formal a una democracia integral, cierta y estable. Allí debe estar el Ombudsman, para garantizar un hacer positivo del Estado; "una actitud del poder que brinde los medios materiales para que, por ejemplo, el derecho al trabajo, a la salud, al bienestar social, a la vivienda y a la seguridad se realicen efectivamente". Y agrega: "esta vigilancia del hacer de la Administración no puede ser obra de los sistemas tradicionales de control jurídico pensados exclusivamente para hacer frente a las violaciones de los derechos políticos y civiles". 
Gros Espiell aprovechó aquella asamblea fundacional del ILO para hacer una dura condena contra la Doctrina de la Seguridad Nacional que había dado sustento ideológico a las aberrantes dictaduras que sufría Latinoamérica, entre ellas su propio país. Sostuvo que no poner límites éticos ni jurídicos al poder va contra la esencia de la república que ha de defenderse de sus enemigos con medios democráticos, dentro del derecho, con las armas de la ley. Invoca para ello el pensamiento del gran filósofo del derecho Gustav Radbruch perseguido por el nazismo quien, al regresar a su cátedra de Heideldberg dijo que ninguna idea de seguridad ni menos del Derecho carece de sentido si no se integra con los valores de la Justicia.

Asocia la lenta recuperación de las instituciones democráticas que se venía operando en América Latina como propicia para el establecimiento de esta institución y afirma que el Ombudsman puede ayudar a restaurar la idea de la Democracia y la fe en el Derecho. Las palabras finales de aquella primera conferencia fueron: "Estimo que si este coloquio, apoyándose científicamente en el prestigio intelectual de las ilustres figuras que en él participan impulsa la idea de estudiar la cuestión del Ombudsman en América Latina y las modalidades jurídicas y prácticas que puede aportar la incorporación a la causa de la Democracia, del Derecho y de la Libertad cumplirá con un gran objetivo. La cuestión no es fácil, las dificultades jurídicas son muchas, los obstáculos políticos pueden ser muy grandes, pero nada de esto obsta a que iniciemos los estudios de fondo, partiendo de la aceptación inicial de la idea de que la creación de una institución del tipo del Ombudsman en América Latina es, en principio deseable y que su establecimiento es útil y puede llegar a ser necesario. Esta es, en definitiva, la conclusión de mi ponencia y la propuesta que me honro en hacer".

Esta apretada síntesis refleja lo que a mi entender son las ideas centrales con las que Gros Espiell lanzaba coadyuvando al propósito de crear las defensorías del pueblo en América Latina. Dos años después se establecería, la primera en Guatemala, y más tarde se sumarían todos los países de la región con excepción de Brasil y Chile. El pensamiento político no crece como las capas geológicas por acumulación, sino dialécticamente y en espiral. Hoy no podríamos entender el sentido de esta institución sin tener en cuenta las variables históricas en torno a las cuales fue creciendo y desarrollando. Seguramente ahora diríamos algunas otras cosas pero el núcleo a partir del cual existe hoy esta institución en Latinoamérica fue éste.

Aquella lección propedéutica de Gros Espiell asoma dudas, explora posibilidades, invita a la discusión, pero con la mirada del pensamiento en acción. Gros Espiell no hace afirmaciones dogmáticas, cerradas, abstractas y definitivas; desafía a la realidad confrontándola con la experiencia, pero sin renunciar a innovación. Aplica lo que el gran jurista alemán Georg Jellinek afirmaba: "No es la mejor doctrina de Derecho Púbico aquella que ofrece la mayor perfección lógica, sino la que explica la realidad política de manera 
más natural". Las defensorías del pueblo, el Ombudsman como se le decía entonces, se planteaba como un desafío a la rigidez institucional de los estereotipos. Era una mirada hacia el porvenir sin prejuicios ni limitaciones. Según nos enseñó José Ortega y Gasset. "El horizonte es una línea biológica, un órgano viviente de nuestro ser; mientras gozamos de plenitud, el horizonte emigra, se dilata, ondula elástico casi al compás de nuestra respiración. En cambio cuando el horizonte se fija, es que se ha anquilosado y que nosotros ingresamos en la vejez". Concluyo que es ésta la gran enseñanza que nos deja el gran jurista que hoy homenajeamos.

Antes y después de su intervención en el ILO, Gros Espiell hizo muchas y muy importantes cosas. Pero permítasenos hoy, a quienes hemos desempeñado o desempeñan hoy tan significativa responsabilidad, poner como tributo a su memoria en ésta que fue su casa, un sentido mensaje de homenaje y gratitud por haber ayudado a nacer y crecer a esta noble institución.

Agradezco a la Presidenta de la Institución Nacional de Derechos Humanos y Defensoría del Pueblo, Mariana Blengio, a la Decana de la Facultad de Derecho de la Universidad de la República, Cristina Mangarelli, a la Defensora de Vecinas y Vecinos de Montevideo María Elena Laurnaga y a nuestra Vicepresidenta I Ana Agostino haberme permitido estar hoy aquí y ser la voz de quien tuvo un papel determinante en la vida del ILO, en el desarrollo y fortalecimientos de las defensorías del pueblo y fundamentalmente así, en la promoción y protección de los derechos humanos.

Montevideo 6 de diciembre de 2019 